\title{
Compatibility study of nanofiltration and reverse osmosis membranes with 1-cyclohexylpiperidenium bicarbonate solutions
}

Birendra Adhikari, Michael G. Jones, Christopher J. Orme, Daniel S. Wendt, Aaron D. Wilson* Idaho National Laboratory, P.O. Box 1625 MS 3732, Idaho Falls, ID 83415-3732, USA

*Corresponding author: Aaron.Wilson@INL.gov

\section{ABSTRACT}

Any forward osmosis (FO) based water treatment process using a thermolytic draw solute requires a method to remove/recycle low concentrations of residual draw solute contained in the product water. For switchable polarity solvent forward osmosis (SPS FO) this means the removal of residual tertiary amines from the product water. This study explores membrane filtration of 1cyclohexylpiperidenium bicarbonate $\left(\mathrm{CHP}-\mathrm{H}_{2} \mathrm{CO}_{3}\right)$ draw solute under conditions relevant to the SPS FO process. Fourteen commercially available nanofiltration (NF) and reverse osmosis (RO) membranes were screened. Several NF membranes displayed good chemical compatibility at $\mathrm{CHP}-\mathrm{H}_{2} \mathrm{CO}_{3}$ concentrations of 2.5 weight percent or higher while maintaining fair selectivity, with flux normalized rejection of $\sim 80-99 \%$ and flux normalized net driving pressure of 80 - 400 psi for the normalized flux of $20 \mathrm{LMH}$. Most sea water and brackish water RO membranes tested showed flux normalized rejection of above $98 \%$ and flux normalized net driving pressure of 300 - 900 psi. A two-pass NF/tap water (TW) RO system is proposed as an effective low-pressure method to remove residual $\mathrm{CHP}-\mathrm{H}_{2} \mathrm{CO}_{3}$ from water. 
Keywords forward osmosis; nanofiltration; reverse osmosis; switchable polarity solvent.

\section{Introduction}

Forward osmosis (FO) is a membrane process that can be combined with other processes to remove dissolved solids from an aqueous solution [1-4]. Water transport is achieved by exposing a semipermeable membrane to a feed solution where water passes to a more osmotically concentrated draw solution. Unless the draw solute is included in the final aqueous product (energy drink or fertigation) the draw solute must be recovered $[5,6]$ in a practical embodiment of the process. It is common in literature to see some form of the claim that FO is a spontaneous low energy process. Generally, this is only true if the energy cost of the solute recovery step is ignored. Even when the recovery is considered it is sometimes demonstrated or considered over an inappropriately low-concentration range which is not representative of a true draw solution regeneration process. There is also the mistaken implication that not using a reverse osmosis (RO) membrane but rather a nanofiltration (NF) or ultrafiltration (UF) membrane to concentrate a solution allows the osmotic/separation energy-cost to be avoided, which is not the case. Even if reverse osmosis (RO) membranes can be avoided, hydraulically driven filtrations to generate osmotically concentrated solutions have an associated fundamental energy of separation cost.

Stimuli-driven (next generation) draw solutes have been developed in part to avoid paying the cost of separation/recovery of the draw through electrical energy via reverse osmosis $\mathrm{RO}$ (and other hydraulically driven filtrations). The other major reason to pursue stimuli-driven draw solutes is to access higher osmotic pressures draw solutions, given single pass RO can 
produce a draw solute with a maximum osmotic pressure of about $800 \mathrm{psi}$. The high osmotic pressure draw solutes allow higher concentration solutions to be treated and higher water recoveries to be achieved. The most significant stimuli-driven solutes are thermally-sensitive solutes [7], which offer the potential for cost savings over hydraulically driven processes because heat is generally lower cost than electricity. Thermally-sensitive solutes include 1) temperaturedependent phase behavior (lower critical solution temperature (LCST) solutes, such as $\mathrm{Na}_{2} \mathrm{HPO}_{4}$ [8] and 2) thermolytic solutes which undergo temperature dependent chemical reactions to drive phase behavior (Ammonia- $\mathrm{CO}_{2}[3,9-11]$ and switchable polarity solvent (SPS)[12-15]). Both processes can be defined by temperature-dependent equilibria. Equilibria correspond to free energy which can be decomposed into largely temperature independent enthalpic and temperature dependent entropic terms, Equation 1, where $R$ is universal gas constant, $T$ is the temperature $(\mathrm{K}), K_{e q}$ is equilibrium constant, ??G is the change in Gibbs free energy, ??H is the change in enthalpy and ??S is the change in entropy.

$$
\begin{aligned}
& -R T \ln \left(K_{e q}\right)=\Delta \mathrm{G}=\Delta \mathrm{H}-\mathrm{T} \Delta \mathrm{S} \\
& K_{e q}=e^{\left(-\frac{\Delta \mathrm{H}}{R T}+\frac{\Delta \mathrm{S}}{R}\right)}
\end{aligned}
$$

Expressing the concentration of solute via thermally-sensitive equilibrium highlights that a solution will always contain a substantial concentration of solute even after a thermally switching event that must be recovered, most likely through an osmotic filtration. This remaining solute, which can be described as the minimum stimuli-driven concentration (MSDC) [7], must 
be achieved within the temperature range relevant to water. The practical temperature window is between 20 and $90{ }^{\circ} \mathrm{C}(293$ and $363 \mathrm{~K})$, and over this range, there is at most a $24 \%$ change in the entropic factor, $\mathrm{T} \Delta \mathrm{S}$, Equation 1. The energy cost of removing solute is fixed by the enthalpic, $\Delta \mathrm{H}$, value but the temperature range over which the concentration dependent separation occurs is defined by the temperature dependent entropic term. Given that the equilibrium is directly dependent on the entropic and enthalpic terms, Equation 2, the temperature dependent dynamic concentration range is ultimately defined by the $\Delta \mathrm{H}$. To raise the maximum concentration while holding the MSDC constant at a fixed value for an ideal system requires the enthalpic term, $\Delta \mathrm{H}$, to increase. Alternatively if the maximum concentration is held constant and the MSDC is lowered, $\Delta \mathrm{H}$ must still increase. There is an order of magnitude difference in the high and low solute concentration for every $\sim 29 \mathrm{~kJ} / \mathrm{mol}$ of increase in $\Delta \mathrm{H}$ in the 293 and $363 \mathrm{~K}$ temperature window, based on Equation 2. As mentioned, the $\Delta \mathrm{H}$ term is where the energy of separation/desalination is paid when using a thermolytic draw solute. The limitations of thermolytic draw solutes will be explored quantitatively in a subsequent publication, but qualitatively the more completely a system switches the more energy, $\Delta \mathrm{H}$, that switch will require and the less efficient the overall process. Thus, optimization of a thermolytic draw solute requires processes to remove the remaining solute that is inaccessible by the rational application of thermal energy. The osmotic filtration of thermolytic draw solute solutions may be performed using RO, nanofiltration (NF), or ultrafiltration (UF) depending on the molecular volume of the solute, which directly impacts rejection. Understanding that an FO process will always need to be paired with osmotic filtration is important for efforts to develop new draw solutes. Selection of the filtration process will vary with the draw solute, but will likely avoid sea water RO 
membranes given that they require a minimum pressure to operate that would negate any energy advantage of using a thermolytic draw solute.

Switchable Polarity Solvent Forward Osmosis (SPS FO) is a process which uses a thermolytic draw solute, namely a water-immiscible tertiary amine to produce a water-soluble tertiary ammonium bicarbonate. 1-cyclohexylpiperdine (CHP) is optimized for use in the SPS FO process; $\mathrm{CHP}$ can be combined with water and $\mathrm{CO}_{2}$ to form 1-cyclohexylpiperdinium bicarbonate $\left(\mathrm{CHP}-\mathrm{H}_{2} \mathrm{CO}_{3}\right)$ draw solute with an osmotic pressure $>7,000$ psi and effectively switched back to the free amine, Equation 3 [7, 12, 13, 16, 17]. However, it cannot be completely switched back for the reasons discussed above. In the case of CHP- $\mathrm{H}_{2} \mathrm{CO}_{3}$, the MSDC is between 1-2 wt \% ( 30-60 psi)

$\mathrm{NR}_{3(\text { org })}+\mathrm{CO}_{2(\mathrm{~g})}+\mathrm{H}_{2} \mathrm{O} \rightleftharpoons \mathrm{HNR}_{3}{ }_{(\mathrm{aq})}+\mathrm{HCO}_{3}^{-}$(aq)

In this work, an iterative two-step osmotic filtration is proposed, where the rejectate from the first membrane separation is returned to the thermal separation process and the rejectate from the second membrane step is looped back to the first membrane. This osmotic filtration system is appropriate for $\mathrm{CHP}-\mathrm{H}_{2} \mathrm{CO}_{3}$ and similar osmotic filtration systems are expected to be necessary for all thermal sensitive solutes based on equilibrium MSDC concentrations of solute.

Commercially available membranes were characterized for their compatibility for with CHP and $\mathrm{CHP}-\mathrm{H}_{2} \mathrm{CO}_{3}$. In particular, fourteen different $\mathrm{NF}$ and $\mathrm{RO}$ membranes were screened for compatibility and to determine process operating requirements. The flux normalized rejection 
(FNR) and the flux normalized net driving pressure (FNNDP) of membrane coupons were explored with short terms studies ( 3 hours) followed by longer term 24 hour studies. Finally module studies were conducted with the most promising candidates.

\section{Experimental}

\subsection{Materials}

1-Cyclohexylpiperidine (CHP) was purchased from Alfa Aesar ${ }^{\circledR}$ (Ward Hill, MA) and used as received. 99.9\% pure carbon dioxide was used for the preparation of $\mathrm{CHP}-\mathrm{H}_{2} \mathrm{CO}_{3}$ from CHP and water. [13] All the membranes used here were received from Sterlitech Corporation (Kent, MA) and used as received. NF membranes used were: i) DOW FILMTEC NF90, ii) DOW FILMTEC NF270, iii) GE Osmonics Duracid iv) GE Osmonics DK, v) GE Osmonics DL, vi) GE Osmonics CK and vii) Nanostone NF4. RO membranes used were: i) DOW FILMTEC BW30, ii) DOW FILMTEC SW30, iii) DOW FILMTEC SW30XLE, iv) DOW FILMTEC TW30 v) Toray 73AC, vi) TriSep ACM1 and vii) Toray 73HA. A high pressure stainless steel (SS) diaphragm pump (Warners Engineering, Inc.; Minneapolis, MN) and high pressure SS membrane module (Sterlitech Corporation; Kent, MA) were used for the coupon tests. A summary of the manufacturer's information for the membranes used in the study has been provided in Table 1. 
Table 1. List of membranes used in our studies.

\begin{tabular}{|c|c|c|c|}
\hline membrane type & classification & $\begin{array}{c}\text { selective layer } \\
\text { polymer }\end{array}$ & test performed \\
\hline DOW FILMTEC BW30 & RO & polyamide & coupon \\
\hline DOW FILMTEC SW30 & RO & polyamide & coupon \\
\hline DOW FILMTEC SW30XLE & RO & polyamide & coupon \\
\hline DOW FILMTEC NF90 & NF & polyamide & coupon \& module \\
\hline DOW FILMTEC NF270 & NF & polyamide & coupon \\
\hline DOW FILMTEC TW30 & RO & polyamide & module \\
\hline Toray 73AC & RO & polyamide & coupon \\
\hline Toray 73HA & RO & polyamide & coupon \\
\hline TriSep ACM1 & RO & polyamide & coupon \\
\hline GE Osmonics CK & $\mathrm{NF}$ & cellulose acetate & coupon \\
\hline GE Osmonics DK & $\mathrm{NF}$ & $\begin{array}{c}\text { thin film (not } \\
\text { specified) }\end{array}$ & coupon \\
\hline GE Osmonics DL & $\mathrm{NF}$ & $\begin{array}{c}\text { thin film (not } \\
\text { specified) }\end{array}$ & coupon \\
\hline GE Osmonics Duracid & $\mathrm{NF}$ & thin film composite & coupon \\
\hline Nanostone NF4 & $\mathrm{NF}$ & polyamide & coupon \\
\hline
\end{tabular}

\subsection{Methods}

$\mathrm{CHP}$ and carbon dioxide were contacted in an aqueous environment to form $\mathrm{CHP}-\mathrm{H}_{2} \mathrm{CO}_{3}$ using the method previously reported by Orme et. al. [12]. A gas chromatography (GC/HP5890) and freezing point osmometer (Advanced Instruments) were used to determine concentration [13]. Isothermal filtration experiments $\left(22 \pm 2^{\circ} \mathrm{C}\right)$ at different pressures were completed for each membrane. The trans-membrane pressures for each membrane ranged from 150 to $350 \mathrm{psi}$. The solutions had variable concentrations of CHP- $\mathrm{H}_{2} \mathrm{CO}_{3}$, ranging from $0.8-12 \mathrm{wt} \%$ in water. A constant cross flow velocity of $15.5 \mathrm{~cm} \mathrm{~s}^{-1}$ of the mixture was maintained for each experiment, which was equivalent to $800 \mathrm{~mL} \mathrm{~min}^{-1}$ for the test apparatus. The Sterlitech high pressure 
filtration module had an inner membrane area of $42 \mathrm{~cm}^{2}$. A high pressure metering pump was used to produce the flow rate and a back-pressure regulator was used to produce the transmembrane pressure across the membrane module. The process flow diagram is featured in Figure 2.

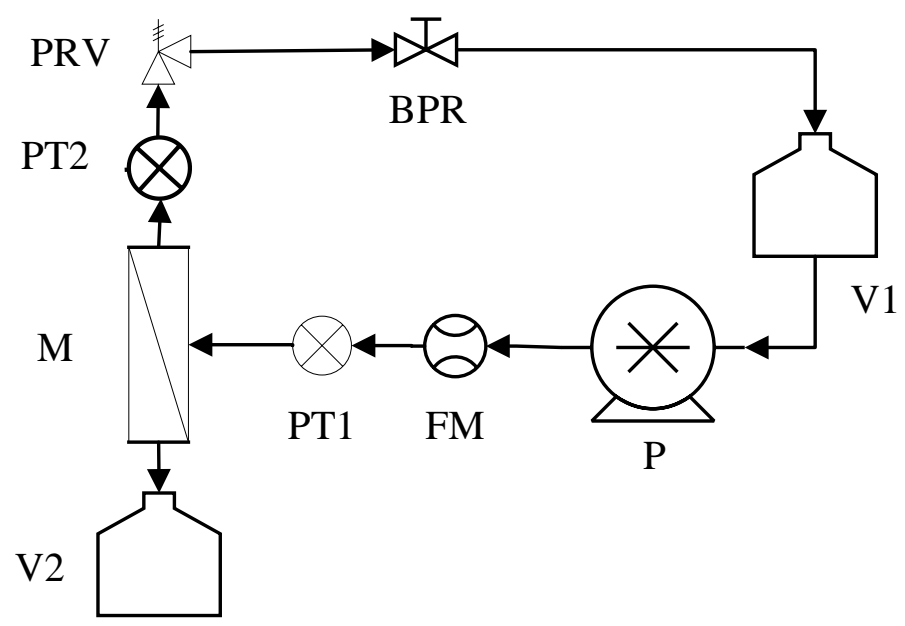

$\begin{array}{llllll}\text { BPR } & \text { Back pressure regulator } & \text { FM } & \text { Flow meter } & \text { M } & \text { Membrane } \\ \text { P } & \text { Pump } & \text { PRV } & \text { Pressure relief valve } & \text { PT1 } & \text { Pressure transducer 1 } \\ \text { PT2 } & \text { Pressure transducer 2 } & \text { V1 } & \text { Feed vessel } & \text { V2 } & \text { Permeate vessel }\end{array}$

Figure 1. Experimental process flow diagram of filtration unit involving NF and RO membranes.

\subsection{Theory}

Water flux through a membrane is defined as the amount of water that passes from one side of the membrane to the other per unit membrane area per unit time, Equation 4 [18].

$$
J_{W}=\frac{\Delta V}{A \Delta t}
$$


where $\Delta V$ is the volume of liquid passed through the membrane $(\mathrm{L}), \mathrm{A}$ is the membrane area $\left(\mathrm{m}^{2}\right)$ and $\Delta t$ is the time interval over which the liquid volume is collected $(\mathrm{h})$.

According to Darcy's law, the water flux is directly proportional to the overall effective pressure difference (hydraulic and osmotic combined) across the membrane and inversely proportional to the mass transfer resistance Equation 5 [15, 19-22].

$$
J_{w}=A \times(\Delta P-\Delta \pi)
$$

where $J_{w}$ is water flux $\left(\mathrm{L} \mathrm{m}^{-2} \mathrm{~h}^{-1}\right), \Delta \pi$ is the osmotic potential of the solution (bar), $\Delta P$ is the transmembrane pressure (bar), A is water permeability constant (A-value or water permeance) and $\Delta P-\Delta \pi$ is the net driving pressure (NDP).

Rearranging Equation (5),

$$
A=\frac{J_{w}}{N D P}
$$

Similarly, the Equation for the solute flux is the following:

$$
J_{s}=B \times\left(C_{f}-C_{p}\right)
$$

where $J_{s}$ is mass of solute passing through the membrane per unit time per unit area $(\mathrm{kg}$ $\left.\mathrm{m}^{-2} \mathrm{~h}^{-1}\right), C_{f}$ is feed concentration $\left(\mathrm{kg} \mathrm{L}^{-1}\right), C_{p}$ is permeate concentration $\left(\mathrm{kgL}^{-1}\right)$ and $\mathrm{B}$ is salt permeability constant (B-value or salt permeance).[23]

Similarly, membrane intrinsic rejection is the percentage of the feed solute that does not passes through the membrane with the permeate, Equation 8 [18]. 
$R=\left(1-\frac{C_{p}}{C_{f}}\right) \times 100$

where $R$ is the membrane intrinsic rejection (\%).

Similarly,

$S P=\frac{C_{p}}{C_{f}}$

where SP is the fraction of solute passage from the feed to the permeate.

Rearranging Equation 7 by applying Equation 9,

$B=J_{w} \frac{S P}{1-S P}$

A constant flux can be used to determine flux normalized rejection (FNR) and flux normalized net driving pressure (FNNDP). The industrially relevant membrane flux of $20 \mathrm{Lm}^{-2} \mathrm{~h}^{-}$ ${ }^{1}$ (LMH) was used to calculate all FNNDP and FNR. FNNDP and FNR help to compare the results on a constant flux situation and compare the energy cost of the membrane-based system.

For a known constant flux,

$F N R=\left(1-\frac{B}{J_{W}+B}\right) \times 100$

where $J w$ is the constant flux and FNR is expressed in $\%$.

Similarly,

$F N N D P=\frac{J_{w}}{A}$ 
where FNNDP is expressed in psi.

The overall productivity is volumetric flow of product water with respect to volumetric flow rate of feed at the specified operating condition.

$$
P=\frac{Q_{p}}{Q_{f}} \times 100
$$

where $\mathrm{P}$ is the productivity (\%) $Q_{p}$ is volumetric flow rate of permeate $\left(\mathrm{L} \mathrm{min}^{-1}\right)$ and $Q_{f}$ is volumetric flow rate of feed $\left(\mathrm{L} \mathrm{min}^{-1}\right)$.

For a membrane element, the concentration of incoming feed is always different than the concentration of exiting feed. Thus, the performance of such elements is always evaluated based on the log average concentration of feed in the module, Equation 14.

$$
\frac{C_{f l a}}{C_{f}}=-\frac{\ln (1-P)}{P}
$$

where $C_{f l a}$ is the log average feed concentration over the entire element.

\section{Results and Discussion}

Scaling up the SPS FO technology, Figure 1, involves optimizing four different processes: 1) gas contacting to form the draw solution, 2) forward osmosis membrane extraction of water, 3) degassing to separate the organic and aqueous phases of the diluted draw solution and 4) separation of clean water from the aqueous phase. The separation of clean water can be further broken into three passes featuring 4a) mechanical liquid separator (decanter), 4b) lowpressure osmotic filtration process, and 4c) an optional polishing column (or oxidative treatment) 
purification. This work addresses step $4 \mathrm{~b}$ the low-pressure osmotic filtration process. Initial membrane compatibility studies with our first generation SPS suggest that SPS should be compatible with the established membranes materials [24].

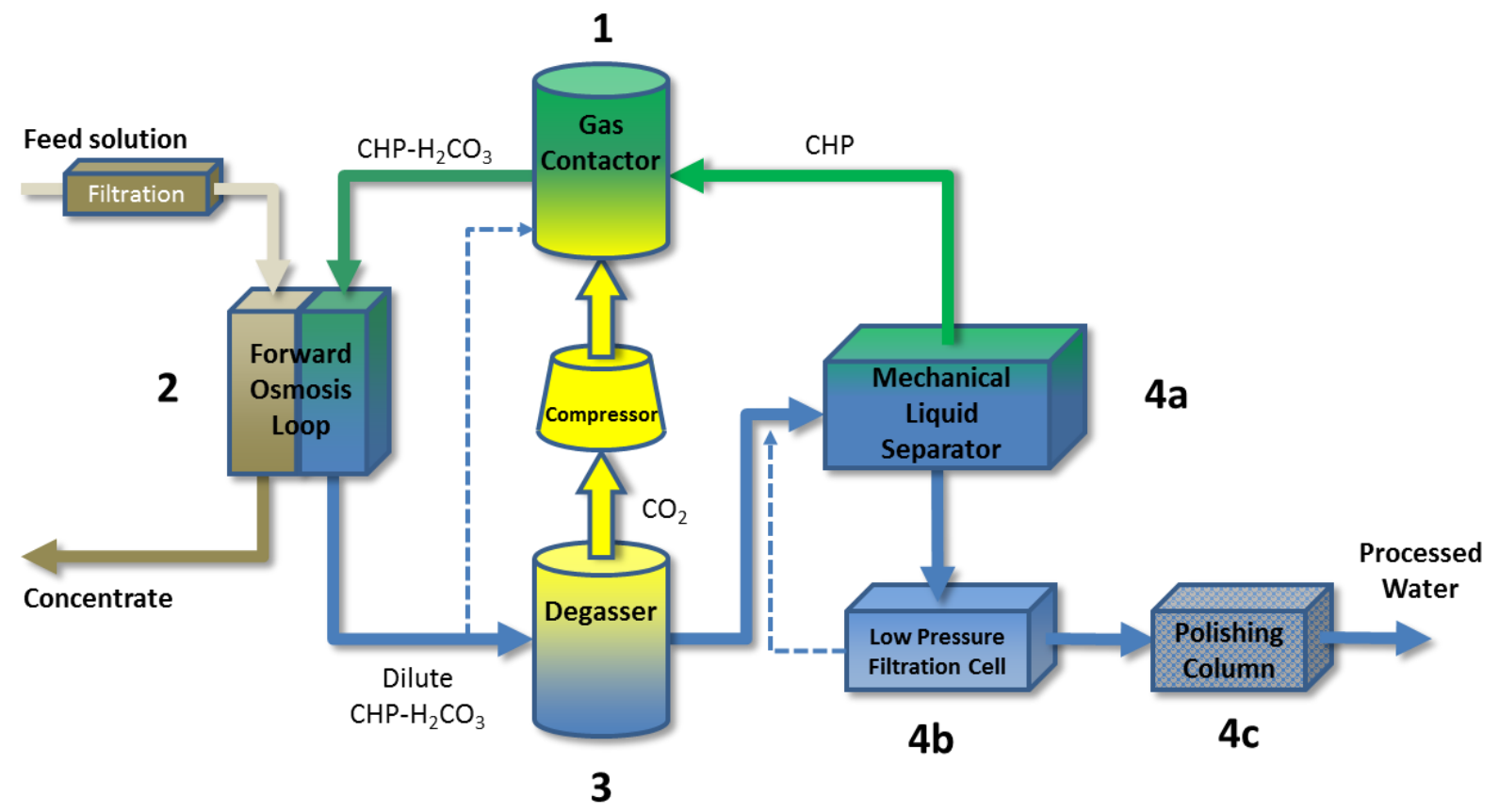

Figure 2. Process flow diagram of SPS FO technology.

The diluted $\mathrm{CHP}-\mathrm{H}_{2} \mathrm{CO}_{3}$ draw solution that emerges from the forward osmosis unit is degassed at $60-80{ }^{\circ} \mathrm{C}$ temperature.[12] The degassing process removes the majority of the $\mathrm{H}_{2} \mathrm{CO}_{3}$ in the form of $\mathrm{CO}_{2}$. The majority of $\mathrm{CHP}$ in the aqueous solution phase separates and can be decanted away but a small amount of CHP- $\mathrm{H}_{2} \mathrm{CO}_{3}, 1-2$ wt $\%$ (osmotic pressure 30-90 psi, Table 2 [13]), is not practical to remove with the degassing because of the inherent thermodynamics of this process. The goal of this research effort is to identify a low-pressure osmotic filtration process for addressing the low concentrations of dissolved tertiary amine and 
tertiary ammonium bicarbonate. The process requires good rejection of the tertiary amine, good permanence, and a membrane that operates at low pressures.

Table 2. Weight percentage, molality, osmolality and osmotic pressure of different $\mathrm{CHP}-\mathrm{H}_{2} \mathrm{CO}_{3}$ solutions at room temperature

\begin{tabular}{|c|c|c|c|}
\hline CHP- $\mathrm{H}_{2} \mathrm{CO}_{3}, \mathrm{w} \%$ & $\mathrm{CHP}-\mathrm{H}_{2} \mathrm{CO}_{3}, m$ & solution osmolality, mOsm & osmotic pressure, $\mathrm{psi}$ \\
\hline 0.1 & 0.004 & 7.65 & 3.03 \\
\hline 1 & 0.044 & 77.1 & 30.6 \\
\hline 2 & 0.089 & 156 & 61.8 \\
\hline 3 & 0.135 & 236 & 93.7 \\
\hline 4 & 0.182 & 318 & 126 \\
\hline 5 & 0.230 & 402 & 159 \\
\hline 10 & 0.485 & 848 & 337 \\
\hline
\end{tabular}

\subsection{Initial NF membranes screening studies}

Chemical compatibility plays a major role in the selection of membranes that must operate in environments rich in low molecular weight organics such as CHP. A membrane process is viable only when the membrane survives in terms of maintaining its selectivity and permeability, usually in excess of hundreds of hours of operation at specified or variable operating conditions [25]. NF membranes were chosen for their manufacturer-rated chemical resistivity in terms of $\mathrm{pH}$ and temperature as well as higher permeance in comparison to the $\mathrm{RO}$ counterparts at much lower operating pressure regimes [26-30]. Organic solvent nanofiltration $(\mathrm{OSN})$ is a maturing membrane-based separation technology that allows discrimination between molecules in the range of approximately 100-2000 Da in organic media (CHP 167 Da and CHP $\mathrm{H}_{2} \mathrm{CO}_{3} 229 \mathrm{Da}$ ). Some OSN membranes can also operate in harsh $\mathrm{pH}$ and temperature 
environments [31]. CHP and CHP- $\mathrm{H}_{2} \mathrm{CO}_{3}$ were not expected to be compatible with all membranes tested.

The initial studies were short experiments focused on the membranes initial flux normalized rejection of $\mathrm{CHP}-\mathrm{H}_{2} \mathrm{CO}_{3}$ and net driving pressure. The purpose was to screen selected membranes that could be candidates for repeated exposures and longer runs. These initial tests used feed solutions that contained 1 - $4 \mathrm{wt} \%$ concentrations of $\mathrm{CHP}-\mathrm{H}_{2} \mathrm{CO}_{3}$. They were carried out at nominal transmembrane pressures of 150 psi. Membranes that survived these filtration tests were characterized for FNR of CHP- $\mathrm{H}_{2} \mathrm{CO}_{3}$ and FNNDP. To understand the variability in the performance and eliminate potential outliers, each of these tests was performed in triplicates.

The FNNDP metric was used in these evaluations because it allows for easy calculation of energy required to conduct a filtration under industrially relevant conditions. In the absence of an energy recovery device (ERD) for a given flux rate the minimum required energy is the product of the volume of solution directed at the filtration system and the FNNDP. In the presence of an ERD the minimum energy required is the product of volume passed through the membrane and FNNDP plus the energy the ERD fails to capture (product of rejected volume, FNNDP, and ERD efficiency). Once this relative energy is normalized to the recovery fraction of a process, various processes can be easily compared.

Most of these membranes displayed reasonable FNR and FNNDP during these short term experiments but showed variations in performance, primarily in terms of FNR, Figure 3 and Table 3. It was not possible to obtain data for GE Osmonics Duracid membrane and post exposure investigation showed delamination of the selective layer. GE Osmonics CK membranes 
showed fair FNR (88.7 \%) and a FNNDP (244 psi), this FNNDP was similar to DOW FILMTEC NF90 however with lower rejection. Nanostone NF4 membrane showed better FNR ( 93.4\%) but modest FNNDP (171.8 psi). While interesting Nanostone NF4 membrane was eliminated from further study because the commercial tubular membranes and/or membrane elements are not currently available. DOW FILMTEC NF90 (FNNDP of 245 psi and FNR of 99.1\%) was selected for further study based on its very high rejection. During the selection period the membranes were differentiated based on a previous analysis that used permeance and absolute rejection rather than FNNDP and FNR. Using permeance and absolute rejection GE Osmonics DL (FNNDP of 174.6 psi and FNR of $85.6 \%$ ) appeared to perform slightly better than GE Osmonics DL (FNNDP of 170.1 psi and FNR of $86.7 \%$ ) and was selected for further study despite the than FNNDP and FNR data suggesting that GE Osmonics DL should be favored. DOW FILMTEC NF270 membrane had FNNDP of 83 psi and fair FNR of $64.7 \%$ with some variability and was studied further based on its very low FNNDP and as a representative of looser NF systems that may have higher chemical robustness, such as ceramic nano-filtration. 


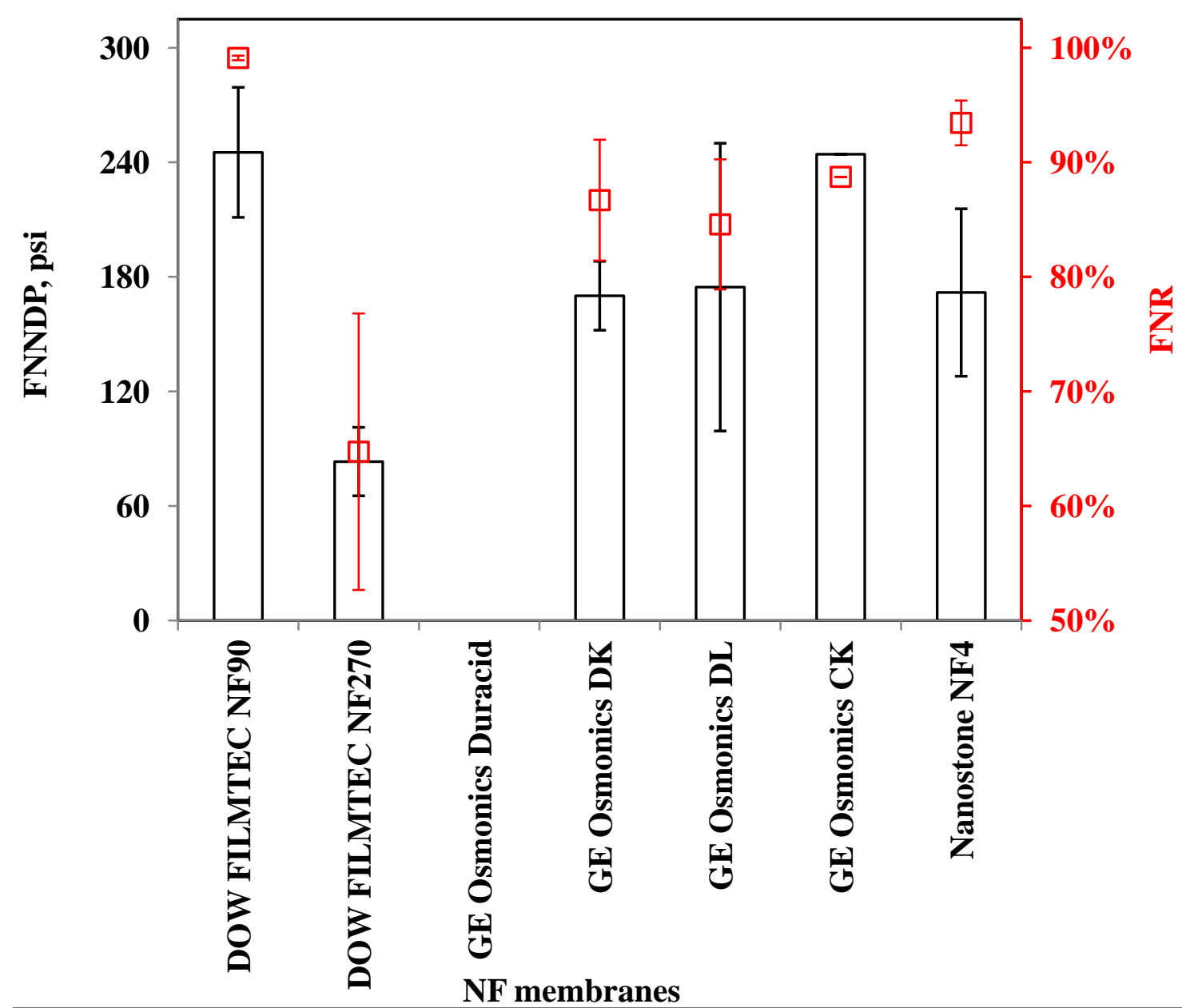

$\square$ Flux normalized net driving pressure

$\square$ Flux normalized rejection

Figure 3. Flux normalized net driving pressure (FNNDP) and flux normalized rejection (FNR) of several nanofiltration membranes screened initially (normalized flux is $20 \mathrm{LMH}$ ). These tests used feed solutions of $4 \mathrm{wt} \% \mathrm{CHP}-\mathrm{H}_{2} \mathrm{CO}_{3}$ against the NF90 and NF270 membranes and 1 wt \% against all other membranes. 
Table 3. Summary of all the membrane experiments

\begin{tabular}{|c|c|c|c|c|}
\hline membrane type & $\begin{array}{c}\text { test } \\
\text { performed }\end{array}$ & $\begin{array}{c}\text { feed concentration, } \\
\text { wt } \% \\
\end{array}$ & FNNDP, psi & FNR, \% \\
\hline DOW FILMTEC BW30 & coupon & 1 & $337 \pm 37.6$ & $99.0 \pm 0.13$ \\
\hline DOW FILMTEC SW30 & coupon & 1 & $932 \pm 36.1$ & $97.9 \pm 0.3$ \\
\hline $\begin{array}{c}\text { DOW FILMTEC } \\
\text { SW30XLE }\end{array}$ & coupon & 1 & $480 \pm 0.0$ & $94.8 \pm 0.0$ \\
\hline \multirow{5}{*}{ DOW FILMTEC NF90 } & \multirow{4}{*}{ coupon } & 1 & $105 \pm 0.0$ & $97.7 \pm 0.0$ \\
\hline & & 3.2 & $215 \pm 0.0$ & $94.9 \pm 0.0$ \\
\hline & & 4 & $242 \pm 0.0$ & $98.1 \pm 0.0$ \\
\hline & & 4.8 & $245 \pm 34.1$ & $99.1 \pm 0.2$ \\
\hline & module & 1.5 & $130 \pm 0.0$ & $98.5 \pm 0.0$ \\
\hline $\begin{array}{c}\text { DOW FILMTEC } \\
\text { NF270 }\end{array}$ & coupon & 4 & $83.2 \pm 17.9$ & $64.7 \pm 0.1$ \\
\hline $\begin{array}{c}\text { DOW FILMTEC } \\
\text { TW30* }\end{array}$ & module & 0.1 & $28.1 \pm 0.0$ & $97.8 \pm 0.0$ \\
\hline Toray $73 \mathrm{AC}$ & coupon & 1 & $823 \pm 10.1$ & $97.3 \pm 0.4$ \\
\hline Toray $73 \mathrm{HA}$ & coupon & 1 & $278 \pm 14.1$ & $97.7 \pm 3.0$ \\
\hline TriSep ACM1 & coupon & 1 & $661 \pm 37.6$ & $86.4 \pm 3.2$ \\
\hline GE Osmonics CK & coupon & 1 & $244 \pm 0.0$ & $88.7 \pm 0.0$ \\
\hline GE Osmonics DK & coupon & 1 & $170 \pm 18.1$ & $86.7 \pm 5.2$ \\
\hline \multirow{2}{*}{ GE Osmonics DL } & \multirow{2}{*}{ coupon } & 1 & $175 \pm 75.4$ & $84.6 \pm 5.7$ \\
\hline & & 2.5 & $201 \pm 27.7$ & $90.0 \pm 2.28$ \\
\hline GE Osmonics Duracid & coupon & 1 & NA & NA \\
\hline Nanostone NF4 & coupon & 1 & $172 \pm 43.9$ & $93.4 \pm 2.0$ \\
\hline
\end{tabular}

*DOW FILMTEC TW30 is anticipated for use at $\mathrm{CHP}-\mathrm{H}_{2} \mathrm{CO}_{3}$ concentration of $0.1 \mathrm{wt} \%$ (1000 ppm) or lower.

\subsection{High concentration nanofiltration studies}

DOW FILMTEC NF90, DOW FILMTEC NF270, and GE Osmonics DL membranes were exposed to higher transmembrane pressures (300 - 350 psi) and feed concentrations (2.5 - 4 wt $\%)$. Figure 4 captures the high end of the osmotic filtration required for the SPS FO process 
where the $\mathrm{CHP}-\mathrm{H}_{2} \mathrm{CO}_{3}$ concentration exiting the mechanical liquid separator is expected to be $0.5-4 \mathrm{wt} \%$. All of these membranes performed consistently over multiple tests. At higher concentrations (4 wt $\%$ ) the GE Osmonics DL membrane had reduced water flux but performed very well at $2.5 \mathrm{wt} \%$ by with 200.8 psi FNNDP and 90\% FNR of CHP- $\mathrm{H}_{2} \mathrm{CO}_{3}$. DOW FILMTEC NF270 membrane performed well with 234 psi FNNDP and 63.98\% FNR of CHP- $\mathrm{H}_{2} \mathrm{CO}_{3}$ with some variability. The DOW FILMTEC NF90 performed with 235 psi FNNDP and 98.1\% FNR of $\mathrm{CHP}-\mathrm{H}_{2} \mathrm{CO}_{3}$ with low variability.

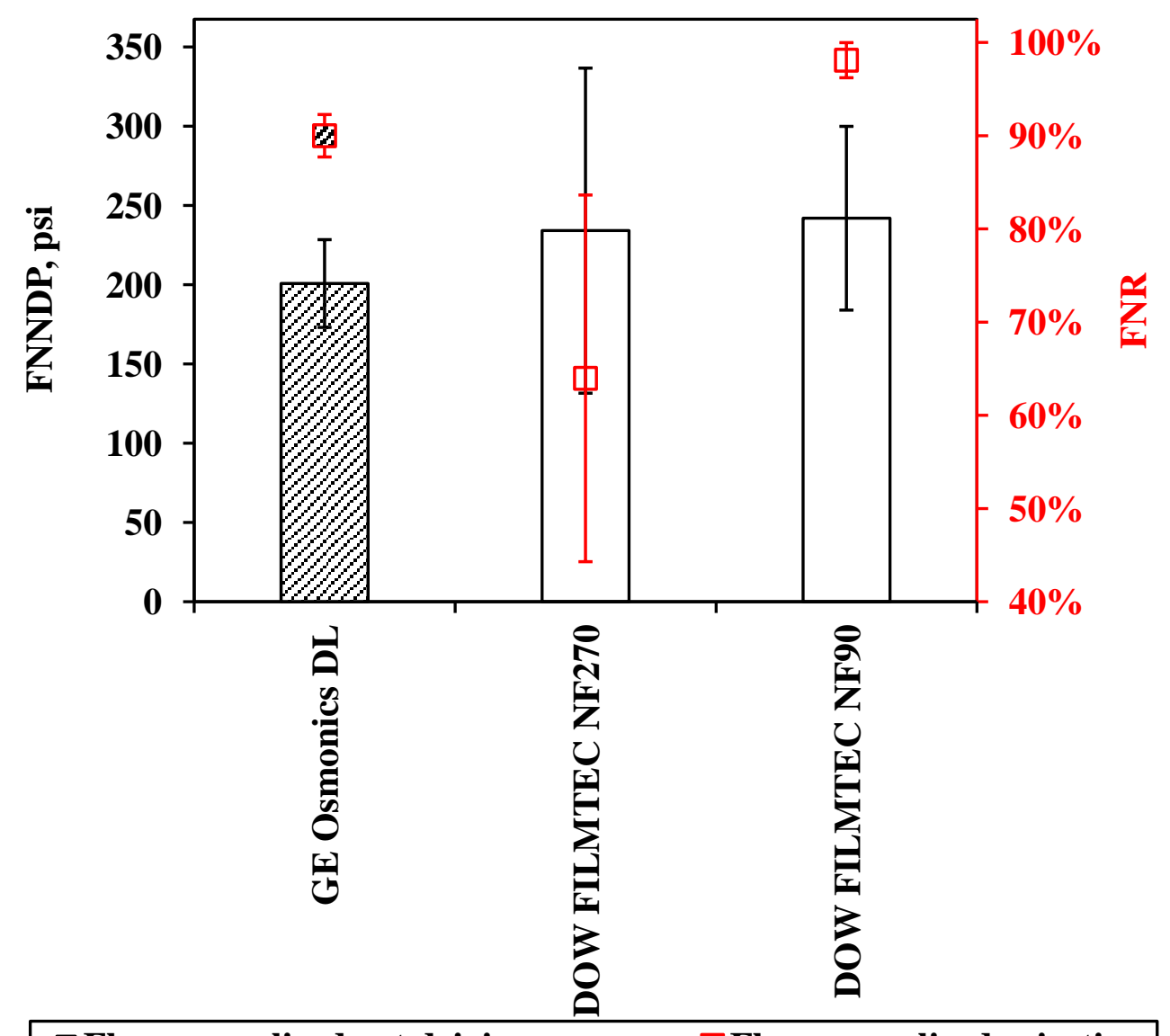

$\square$ Flux normalized net driving pressure $\square$ Flux normalized rejection

Figure 4. Flux normalized net driving pressure and flux normalized rejection of select nanofiltration membranes (normalized flux is $20 \mathrm{LMH}$ ). The patterned bar represents filtration 
with $2.5 \mathrm{wt} \% \mathrm{CHP}-\mathrm{H}_{2} \mathrm{CO}_{3}$ and the non-patterned bar represents filtration with $4 \mathrm{wt} \% \mathrm{CHP}$ $\mathrm{H}_{2} \mathrm{CO}_{3}$.

Because of less variance seen with the DOW FILMTEC NF90, we tested this membrane at different feed concentrations, Figure 5. These feed concentrations were $1.8-4.8$ wt $\%$ CHP$\mathrm{H}_{2} \mathrm{CO}_{3}$. The DOW FILMTEC NF90 performed very well by rejecting more than $90 \%$ on each of these tests. FNNDP increased from 105 psi to 370 psi.

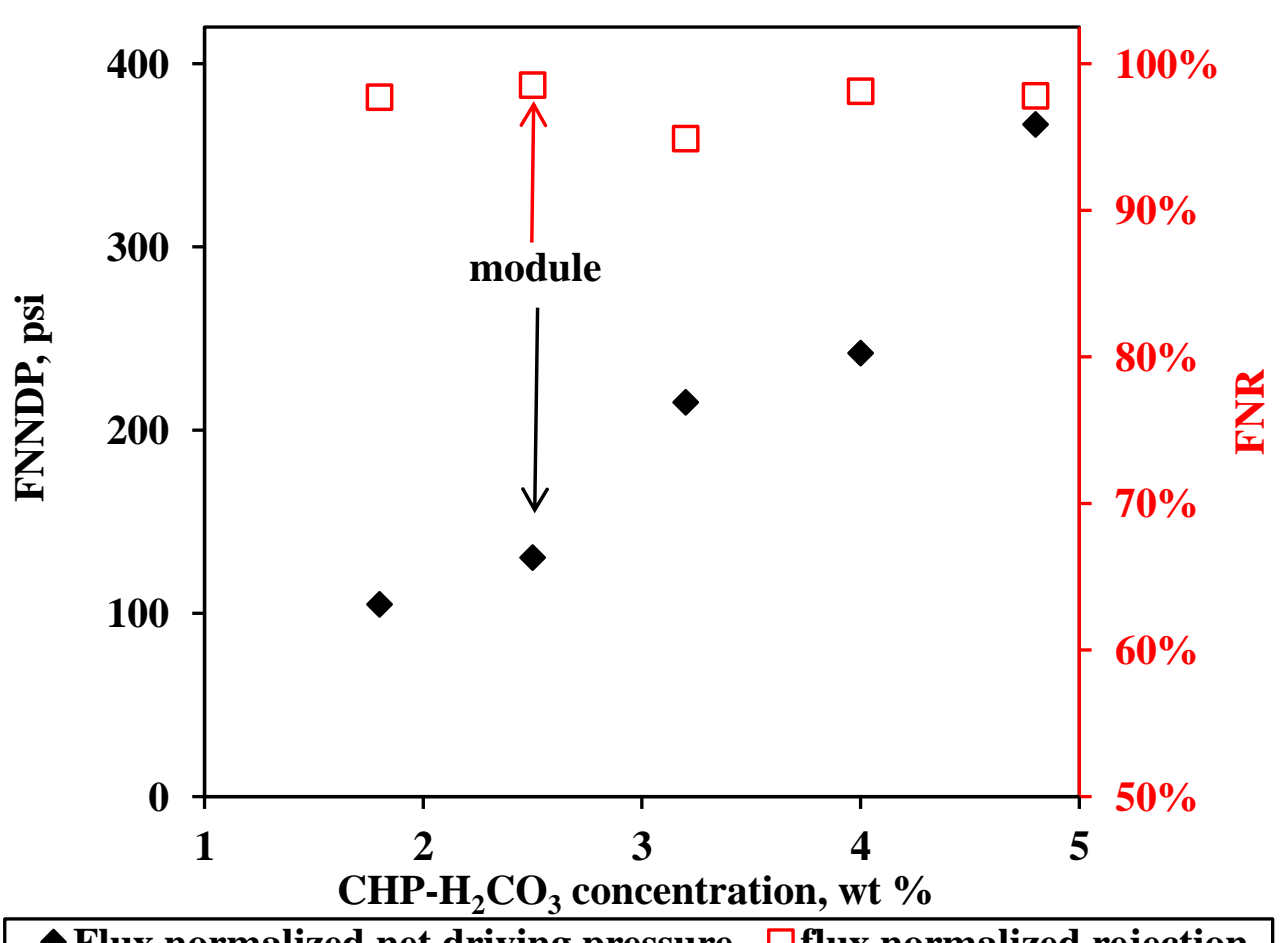

Figure 5. DOW FILMTEC NF90 membrane flux normalized net driving pressure and flux normalized rejection using at transmembrane pressure of 150 - $350 \mathrm{psi}$, normalized flux is 20 LMH, coupon studies unless otherwise specified. The results from modules studies are labeled (see Section 3.6). 


\subsection{Initial RO membrane studies}

For the SPS FO process to be cost effective it needs to recycle virtually all the tertiary amine and, for most applications the product water can only accommodate trace amounts of the amine with target levels in the parts per billion or trillion [14]. Achieving very low concentrations of $\mathrm{CHP}$ or $\mathrm{CHP}-\mathrm{H}_{2} \mathrm{CO}_{3}$ in the permeate stream was expected to require an $\mathrm{RO}$ membrane; the high selectivity of NF90 in the relevant concentration range was not expected. Based on these expectations RO membranes were explored in parallel to the NF membranes to determine their compatibility and selectivity for $\mathrm{CHP}-\mathrm{H}_{2} \mathrm{CO}_{3}$ solution, generally at lower concentration than in NF membranes. This screening included DOW FILMTEC BW30, DOW FILMTEC SW30, Toray 73AC and TriSep ACM1 membranes.

All of these tests were performed at $1 \% \mathrm{CHP}-\mathrm{H}_{2} \mathrm{CO}_{3}$ solution concentration and transmembrane pressure of 300-350 psi. After exposure to $\mathrm{CHP}-\mathrm{H}_{2} \mathrm{CO}_{3}$ the Toray $73 \mathrm{HA}$ membranes showed signs of delamination of selective layer and tore during removal form the cell. Prior to removal from the cell, it showed FNR of $97.0 \%$ and FNNDP of 823 psi. Toray 73AC membranes showed FNR of $97.7 \%$ and FNNDP of 277 psi. DOW FILMTEC BW30 showed FNNDP of 337 psi and FNR of 99.1\%. DOW FILMTEC SW30XLE membrane showed FNNDP of 480 psi and FNR of 95.0\%. TriSep ACM1 displayed FNR above $86.3 \%$ and FNNDP of 651 psi. Results are summarized in Figure 6. 


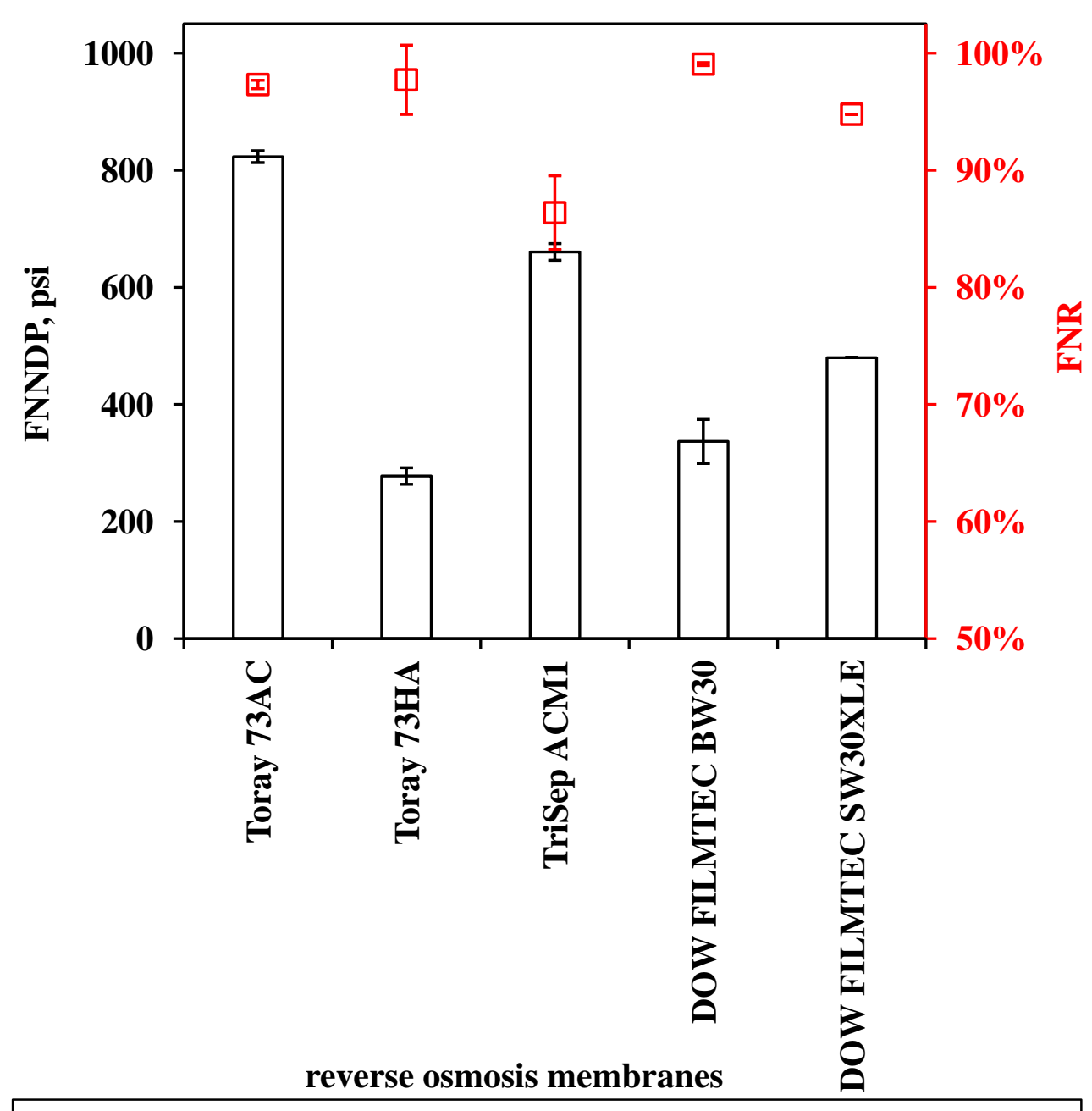

$\square$ Flux normalized net driving pressure $\square$ Flux normalized rejection

Figure 6. RO membrane test results using several commercially available membranes (normalized to the flux of $20 \mathrm{LMH}$ at $1 \mathrm{wt} \% \mathrm{CHP}-\mathrm{H}_{2} \mathrm{CO}_{3}$ ).

\subsection{Long term membrane filtration tests}

Prolonged exposure studies were conducted on promising membranes that were selected based on their commercial module availability and chemical resistance. The membranes selected were DOW FILMTEC NF90, DOW FILMTEC NF270, DOW FILMTEC BW30 and DOW 
FILMTEC SW30. All the membranes were exposed to $1 \mathrm{wt} \% \mathrm{CHP}-\mathrm{H}_{2} \mathrm{CO}_{3}$ feed at $300 \mathrm{psi}$ transmembrane pressures, Figure 7.

All of these membranes survived with FNR above $90 \%$ except for DOW FILMTEC NF270 which had FNR of 74.8\%. DOW FILMTEC SW30 had FNR of $97.9 \%$ and FNNDP of 932 psi whereas DOW FILMTEC BW30 had the FNR of 98.3\% and FNNDP of 283 psi. DOW FILMTEC NF90 showed FNR of $97.4 \%$ and FNNDP of 340 psi on these conditions. These tests were used to determine which modules to select for the modular filtration tests.

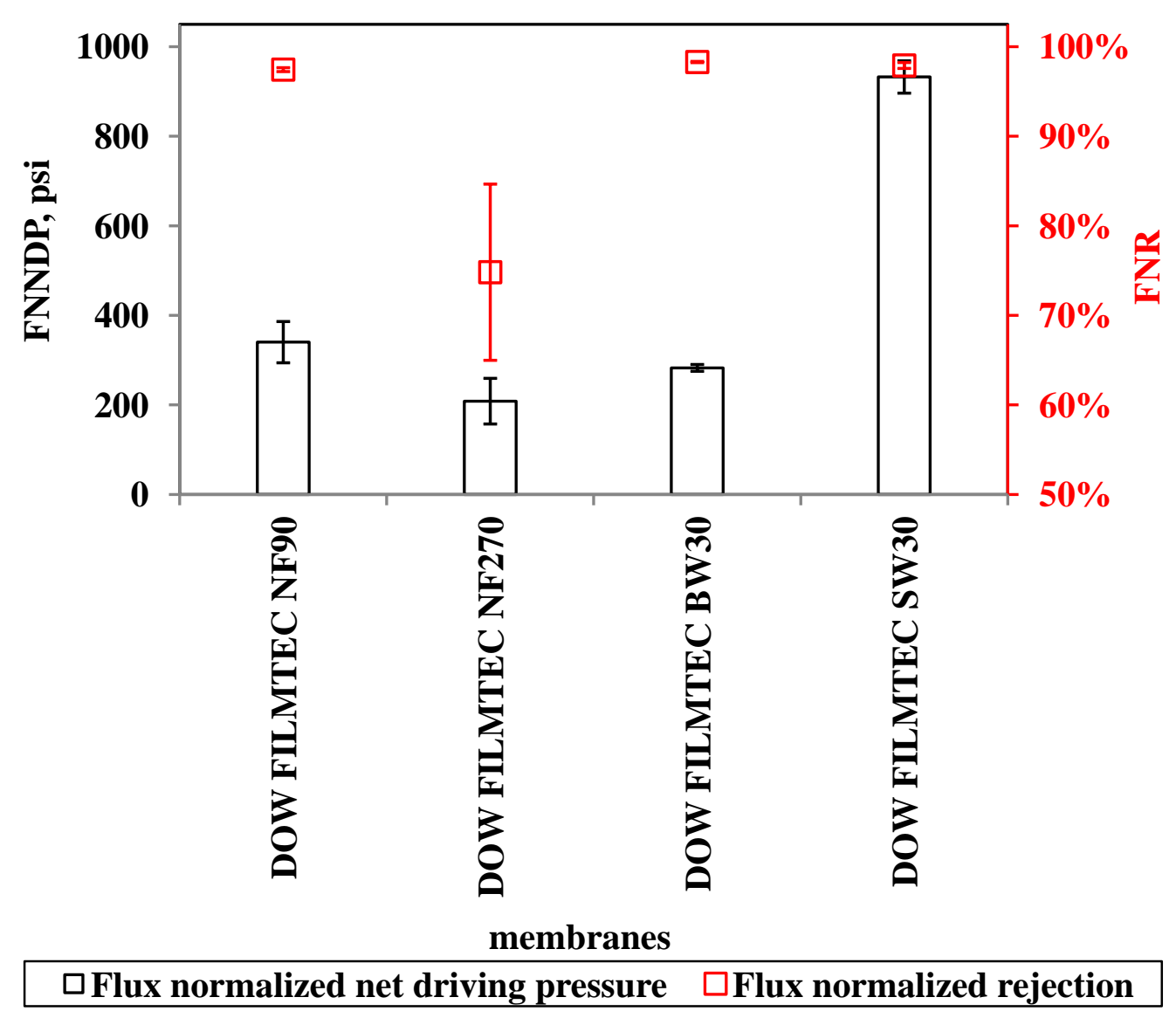

Figure 7. FNNDP and FNR of DOW FILMTEC membranes: NF90, NF270, BW30 and SW30 (normalized to $20 \mathrm{LMH}$ at $1 \mathrm{wt} \% \mathrm{CHP}-\mathrm{H}_{2} \mathrm{CO}_{3}$ ). 


\subsection{Membrane module filtration tests}

With viable membranes identified, efforts transitioned from coupon testing to module studies. The modules studies ensure material compatibility and collect the information necessary to scale the process. The modular studies were performed as a continuous system: The feed had a constant $\mathrm{CHP}-\mathrm{H}_{2} \mathrm{CO}_{3}$ inlet concentration and flow rate and this was balanced by the combined permeate and rejectate flow rate. This change in methodology is required because of a significant increase in membrane surface area when transitioning form coupon to module studies $\left(0.0042 \mathrm{~m}^{2}\right.$ vs. $1.0 \mathrm{~m}^{2}$ ). Since reducing the $\mathrm{CHP}-\mathrm{H}_{2} \mathrm{CO}_{3}$ concentration in the permeate water is a necessity and none of the membranes showed the potential to decrease the concentration to $1 \mathrm{ppm}$ $(0.00001 \mathrm{wt} \%)$ or below, a two- or potentially three-pass filtration system is envisioned. The chemically robust DOW FILMTEC NF90 can serve as a first pass membrane. The second pass could have been the BW30 membrane; however for the process to be cost effective it needs a membrane whose minimum operating pressure matches the negligible osmotic pressures involved in reaching trace levels of tertiary amine. Based on the trend observed for DOW's seawater (SW) and brackish water (BW) membranes this effort explored the tap water reverse osmosis (TW RO) membrane which is designed for lower concentration, higher permeance, and lower minimum operating pressure. Thus, the modules used were DOW FILMTEC NF90 (1.4 $\mathrm{m}^{2}$ membrane area) and DOW FILMTEC TW30 ( $1 \mathrm{~m}^{2}$ membrane area $)$.

The advantage of using low minimum pressure membranes is that depending upon the concentration of feed; the filtration can be performed at or close to the minimum operating pressure range. While choosing the membranes, minimum operating pressure must be 
considered. For example, operating a sea water membrane at 500 psi that gives a FNR of $99.9 \%$ is much more energetically expensive than operating an NF/TW RO two-pass configuration at 200 psi feed side pressure with rejections of $95 \%$ and $98 \%$ for an overall FNR of $99.9 \%$. The manufacturer assigned operating conditions of these membranes are detailed in Table 1. Weight percentage, molality, osmolality and osmotic pressure of different $\mathrm{CHP}-\mathrm{H}_{2} \mathrm{CO}_{3}$ solutions at room temperature are illustrated in Table 4.

Table 4. Operating range and manufacturer specified salt rejection of some selected membranes

\begin{tabular}{|c|c|c|}
\hline Membrane type & $\begin{array}{c}\text { Manufacturer specified } \\
\text { salt rejection, } \%\end{array}$ & $\begin{array}{c}\text { Operating } \\
\text { range, psi }\end{array}$ \\
\hline DOW FILMTEC SW30 & 99.4 & $800-1000$ \\
\hline DOW FILMTEC BW30 & 99.5 & $225-600$ \\
\hline DOW FILMTEC TW30 & 98.0 & $25-150$ \\
\hline DOW FILMTEC NF90 & 97.0 & $70-600$ \\
\hline DOW FILMTEC NF270 & 97.0 & $70-600$ \\
\hline
\end{tabular}

Before performing each experiment, these membrane modules were conditioned by flushing them with DI water. After that, each membrane was conditioned by running a filtration that involved $1000 \mathrm{ppm}(0.1 \mathrm{wt} \%)$ SPS for two hours at 150 psi TMP for DOW FILMTEC NF90 and $30 \mathrm{psi}$ for DOW FILMTEC TW30 at feed flow rate of $1.5 \mathrm{~L} \mathrm{~min}^{-1}$. Filtrations were then carried out by running the filtration experiments for two hours each by recycling both reject and permeate back to the feed tank to maintain a desired feed concentration throughout the experiment. Permeate and feed samples were collected every ten minutes and analyzed. For the DOW FILMTEC NF90 module test, the recirculation flow rate of $1.5 \mathrm{~L} \mathrm{~min}^{-1}$ was maintained and 150 psi of transmembrane pressure was applied throughout the experiment. For DOW 
FILMTEC TW30 module test, recirculation rate of $1.5 \mathrm{Lmin}^{-1}$ was maintained and 25 psi of transmembrane pressure was applied throughout the experiment.

The DOW FILMTEC NF90 membrane performed exceedingly well during the modular tests: FNR of $>98.5 \%$ and FNNDP of 130 psi were achieved during all three separate runs. The feed solution concentration was $1.5 \mathrm{wt} \%$ which corresponds to a realistic practical solution concentration.[12, 15] The DOW FILMTEC TW30 membrane module was exposed to 2,000 ppm (0.2 wt $\%)$ CHP- $\mathrm{H}_{2} \mathrm{CO}_{3}$ solution. This membrane module had average FNR of $97.8 \%$ and FNNDP of 28 psi averaged over three separate runs.

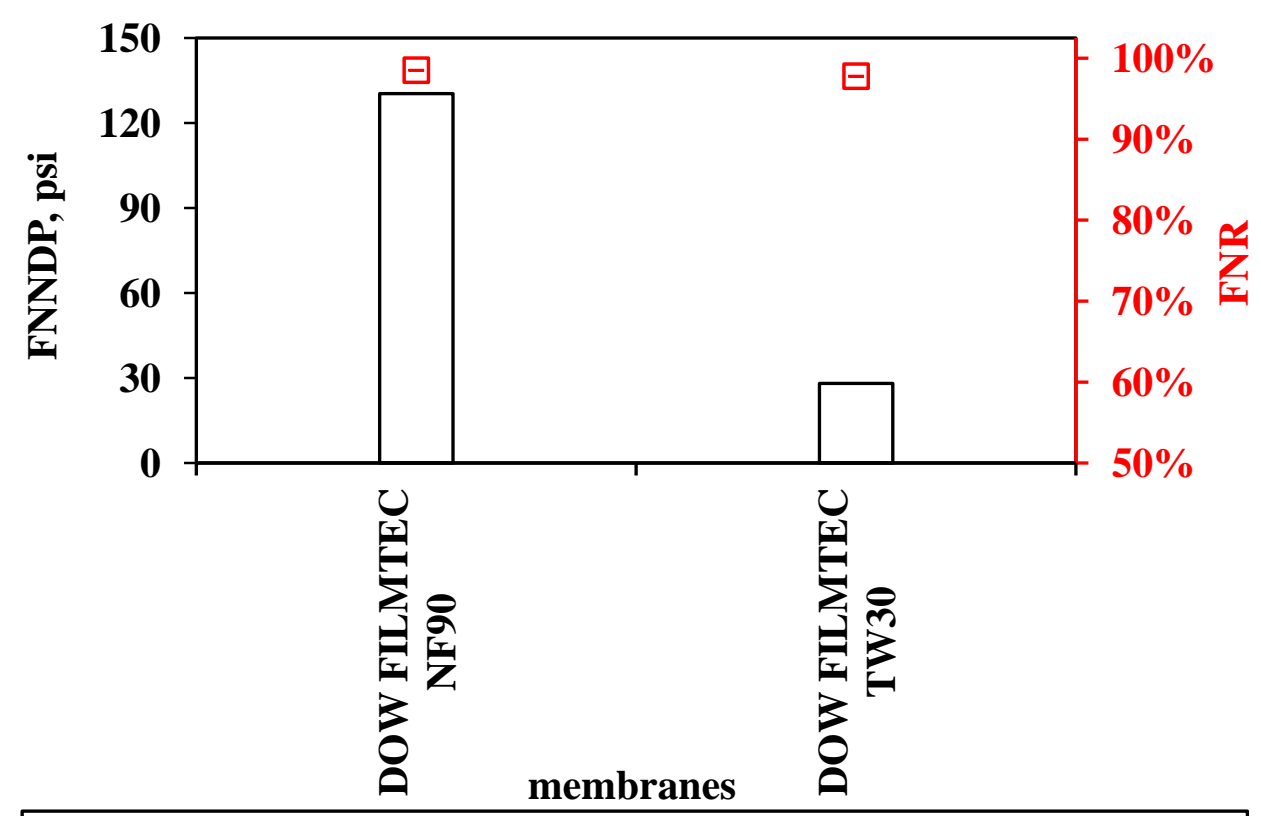

$\square$ Flux normalized rejection $\square$ Flux normalized net driving pressure

Figure 8. Summary of module filtration studies using DOW FILMTEC NF90 and DOW FILMTEC TW30 membrane modules. The DOW FILMTEC NF90 module was exposed to a feed of $1.5 \mathrm{wt} \% \mathrm{CHP}-\mathrm{H}_{2} \mathrm{CO}_{3}$ solution and the DOW FILMTEC TW30 module was exposed to a feed of 2,000 ppm (0.2 wt \% $\mathrm{CHP}-\mathrm{H}_{2} \mathrm{CO}_{3}$ solution and the results are normalized to $20 \mathrm{LMH}$. 


\subsection{Design and implementation of multi-pass process}

Early in the scoping studies it was observed during post-operation inspection that RO membranes exposed to high concentrations of $\mathrm{CHP}-\mathrm{H}_{2} \mathrm{CO}_{3}$ formed a film on the membrane surface (presumably organic CHP). It is believed that this film reduced both permeability and selectivity. In addition to immediate reduction in performance, it is expected that this film would damage the membrane over time. This is the reason that NF membranes were explored for the initial removal of the bulk of the SPS. NF membranes are extremely chemical resistant, but because of their relatively loose pore structure, their overall rejection is not as high as RO membranes. However, some of the NF membranes tested performed well with high rejection at high $\mathrm{CHP}-\mathrm{H}_{2} \mathrm{CO}_{3}$ concentrations with $\mathrm{FNR} \geq 90 \%$. Given that NF membranes have very good chemical compatibilities and relatively low operation pressures and tap water RO membranes have very low minimum operating pressures, low cost, and compatibility with low concentrations of CHP- $\mathrm{H}_{2} \mathrm{CO}_{3}$ it possible to envision multi-pass process. A multi-pass separation system comprised of an NF module (or modules) followed by a TW RO module (or modules) is expected to be cost effective. In such a system, the NF membrane is exposed to high concentrations of low-molecular-mass organics in the first pass and the RO membrane with a lower minimum operating pressure can provide further purification in the second pass where the osmotic pressure is negligible. A single pump that can generate head pressure of $200 \mathrm{psi}$ can be very effective in this situation as numerous studies have already proven that staging membrane systems is often more robust and cost effective [32,33]. By doing this, we can reject more than 99.9\% tertiary amine bicarbonates from the product water. A three-pass membrane system is also a possibility where NF membrane can be followed by two TW RO membranes depending upon 
the purity of water required in the permeate stream. Figure 9 provides a schematic illustrating the staging of the filtration system.

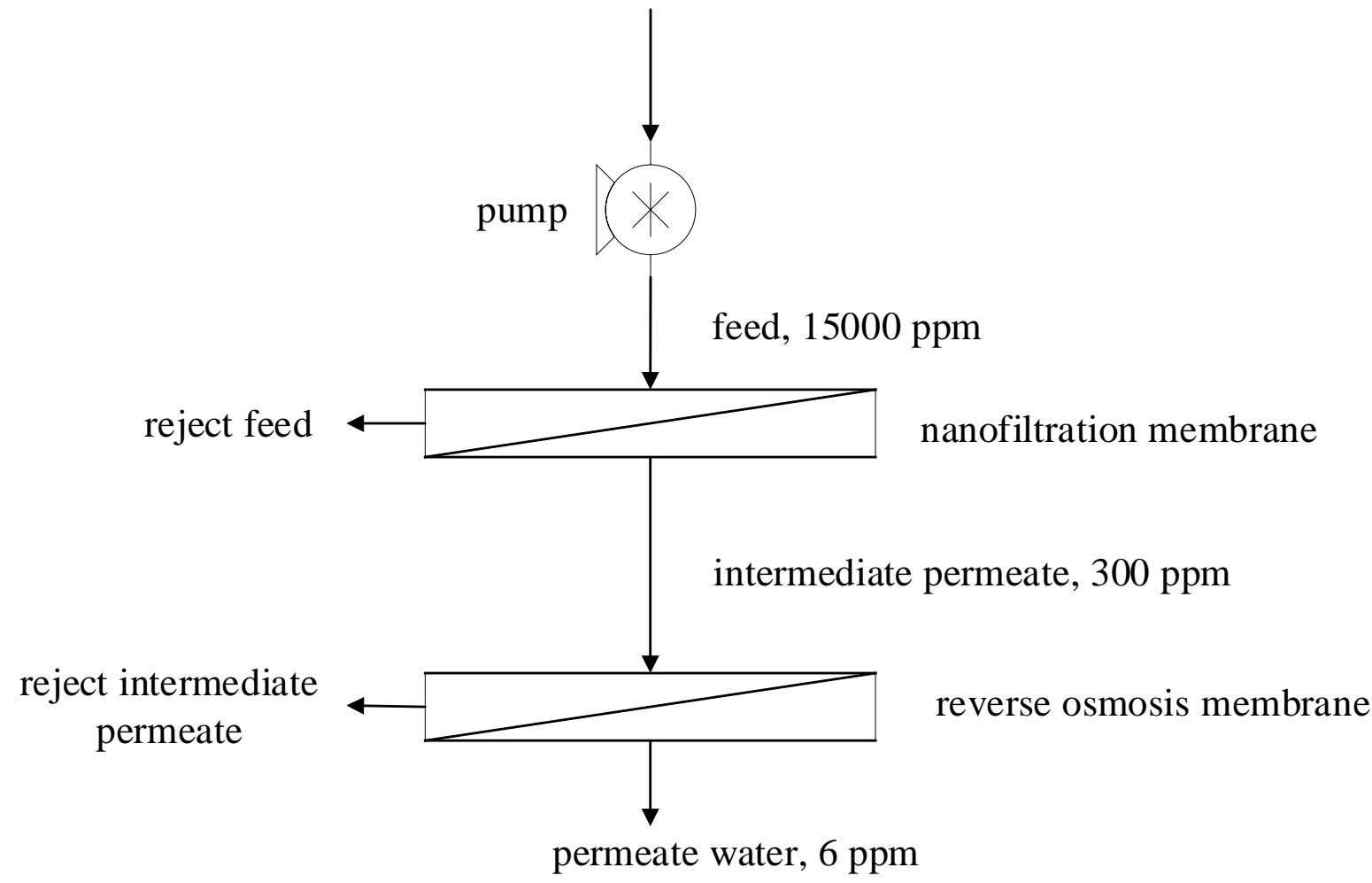

Figure 9. Two-pass membrane system with NF and RO membranes in series.

Using this proposed two/three-pass system, a rough model for the purification can be developed for $1.5 \mathrm{wt} \%$ of $\mathrm{CHP}-\mathrm{H}_{2} \mathrm{CO}_{3}$ solution. In the first pass, DOW FILMTEC NF90 membrane produces the permeate by rejecting $>98 \% \mathrm{CHP}-\mathrm{H}_{2} \mathrm{CO}_{3}$ while operating at 150 psi transmembrane pressure. The modeled recovery of this pass is $\sim 75 \%$. The log average concentration of the feed in the first pass is $2.77 \mathrm{wt} \%$ of $\mathrm{CHP}-\mathrm{H}_{2} \mathrm{CO}_{3}$ solution. In the second pass, a DOW FILMTEC TW30 membrane module produces the permeate by rejecting > $98 \%$ 
CHP- $\mathrm{H}_{2} \mathrm{CO}_{3}$. The modeled recovery of this pass is $\sim 90 \%$. The inlet feed concentration of this pass is $0.03 \mathrm{wt} \%$ of $\mathrm{CHP}-\mathrm{H}_{2} \mathrm{CO}_{3}$. The average concentration of the feed in the first pass is 0.095 wt $\%$ CHP- $\mathrm{H}_{2} \mathrm{CO}_{3}$ solution. Altogether, these two membranes in series can produce permeates with $99.96 \%$ overall rejection of $\mathrm{CHP}-\mathrm{H}_{2} \mathrm{CO}_{3}$ and overall recovery above $68 \%$. This recovery of $68 \%$ represents a baseline for industrial relevance and further improvement. The reject from the pass involving DOW FILMTEC NF90 goes back to the draw solution thermal treatment and the reject from the pass involving DOW FILMTEC TW30 goes back to the DOW FILMTEC NF90 module. Another TW30 membrane module can be added in series which can effectively reject > 98\% of $\mathrm{CHP}-\mathrm{H}_{2} \mathrm{CO}_{3}$. The overall rejection of this three-pass system can be well above $99.9992 \%$ of $\mathrm{CHP}-\mathrm{H}_{2} \mathrm{CO}_{3}$. For the feed stream of water that has $1.5 \mathrm{wt} \% \mathrm{CHP}-\mathrm{H}_{2} \mathrm{CO}_{3}$, the final permeate from the two-pass systems is $6 \mathrm{ppm}(0.0006 \mathrm{wt} \%)$ with a total transmembrane pressures of 175 psi and three-pass systems $0.12 \mathrm{ppm}(0.000012 \mathrm{wt} \%)$ of $\mathrm{CHP}-\mathrm{H}_{2} \mathrm{CO}_{3}$ a total transmembrane pressures of $200 \mathrm{psi}$. There is generally an added cost with most multi-pass/stage systems that is incurred with the introduction of additional pumps; because the proposed two/three-pass systems can be driven with a single pump they avoid the majority of the cost associated with staging. If further reduction in the CHP concentration is required it can be removed with a stationary phase (such as activated carbon) or an oxidative treatment, both of which are currently being studied.

An integrated two-pass NF/TW RO system was built and performed filtration at $150 \mathrm{psi}$ overall pressure using a $1.5 \mathrm{wt} \%$ feed solution. The NF side feed pressure was $100 \mathrm{psi}$ and the TW RO side feed pressure was 50 psi and achieved a FNR of $99.8 \%$. Using single modules it was impractical to balance membrane surface area requirements and so each step was also studied separately. In the first experiment, a constant feed side flow rate of $\sim 0.5$ gallons per 
minute (GPM) of $1.5 \mathrm{wt} \% \mathrm{CHP}-\mathrm{H}_{2} \mathrm{CO}_{3}$ was directed to the NF module of which $\sim 0.15 \mathrm{GPM}$ of nanofiltration concentrate was recycled back to the NF feed tank as (recovery fraction 71\%). Based on this performance $0.045 \mathrm{wt} \%$ would be directed to the TW RO module however to address limited analytical sensitives the TW RO experiment used an elevated concentration of $0.2 \mathrm{wt} \% \mathrm{CHP}-\mathrm{H}_{2} \mathrm{CO}_{3}$. In the second experiment, a constant feed side flow rate of $\sim 0.3 \mathrm{GPM}$ feed of $0.2 \mathrm{wt} \% \mathrm{CHP}-\mathrm{H}_{2} \mathrm{CO}_{3}$ was directed to the TW RO module of $\sim 0.09$ GPM of concentrate was rejected back to the TW RO feed tank and $\sim 0.2$ GPM was extracted as permeate. This was a experimental recovery fraction $55 \%$ starting form $0.2 \mathrm{wt} \% \mathrm{CHP}-\mathrm{H}_{2} \mathrm{CO}_{3}$ but would represent a recovery of $90 \%$ starting from $0.045 \mathrm{wt} \%$ emerging from the NF permeate. Each experiment was performed for 6 hours. Samples were collected at various intervals from the feed and permeate then analyzed with gas chromatography and a freezing point osmometry to ensure consistent performance and determine FNR. The NF side average FNR for $\mathrm{CHP}-\mathrm{H}_{2} \mathrm{CO}_{3}$ solution was 97.0\% and the TW RO average FNR was 97.0\%. The overall NF/RO FNR for CHP- $\mathrm{H}_{2} \mathrm{CO}_{3}$ solution was $99.9 \%$ and overall modeled water recovery of $\sim 64 \%$. This generally matches our baseline case which is industrial feasible in our technoeconomic analysis and from which further optimizations can be achieved.

\section{Conclusions}

Several NF and RO membranes were tested to compare and contrast their chemical compatibility in a filtration environment with $\mathrm{CHP}-\mathrm{H}_{2} \mathrm{CO}_{3}$ at different filtration conditions. Some membranes showed good compatibility while others showed low selectivity and high net normalized driving pressure following exposure to dilute $\mathrm{CHP}-\mathrm{H}_{2} \mathrm{CO}_{3}$. A two-pass NF/RO 
membrane system is well suited for recovering residual SPS from the mechanical separator outlet stream, and this configuration can also solve the materials compatibility issues of RO membranes at higher $\mathrm{CHP}-\mathrm{H}_{2} \mathrm{CO}_{3}$ concentrations. Because of thermodynamic limits on removing a stimulidriven draw solute through a thermal process a final osmotic filtration process such as discussed here is expected to be required for all FO processes using a thermolytic draw solutes.

\section{Acknowledgements}

This work was supported by the United States Department of Energy through contract DE-AC07-05ID14517. Funding was supplied by the Department of Energy (DOE) Office of Energy Efficiency and Renewable Energy (EERE) Geothermal Technologies Office (GTO).

\section{Abbreviations}

$\begin{array}{ll}\text { CHP } & \text { 1-cyclohexylpiperidine; } \\ \text { CHP- } \mathrm{H}_{2} \mathrm{CO}_{3} & \text { 1-cyclohexylpiperidenium bicarbonate; } \\ \text { ERD } & \text { energy recovery device } \\ \text { FNNDP } & \text { flux normalized net driving pressure (psi); } \\ \text { FNR } & \text { flux normalized rejection (\%); } \\ \text { NF } & \text { nanofiltration; } \\ \text { SPS } & \text { switchable polarity solvent } \\ \text { SPS FO } & \text { switchable polarity solvent forward osmosis; } \\ \text { RO } & \text { reverse osmosis; } \\ c_{f} & \left.\text { feed concentration (moles } L^{-1}\right) ;\end{array}$




$\begin{array}{ll}c_{p} & \text { permeate concentration }\left(\text { moles } \mathrm{L}^{-1}\right) ; \\ ? ? P & \text { applied hydraulic pressure (bar or psi); } \\ ? ? \pi & \text { osmotic pressure of the solution (bar or psi); } \\ \text { GPM } & \text { gallons per minute; } \\ J_{w} & \text { permeate flux }\left(\mathrm{L} \mathrm{m}^{-2} \mathrm{~h}^{-1}\right) ; \\ ? ? V & \text { volume of permeate collected }(\mathrm{L}) ; \\ ? ? t & \text { time of the permeate collection }(\mathrm{h} \text { or } \mathrm{s}) ; \\ \text { MSDC } & \text { minimum stimuli-driven concentration }\end{array}$

\section{References}

[1] D.L. Shaffer, N.Y. Yip, J. Gilron, M. Elimelech, Seawater desalination for agriculture by integrated forward and reverse osmosis: Improved product water quality for potentially less energy, J Membrane Sci, 415 (2012) 1-8.

[2] J.R. McCutcheon, M. Elimelech, Forward (direct) osmosis desailination using polymeric membranes., Abstr Pap Am Chem S, 228 (2004) U633-U633.

[3] J.R. McCutcheon, R.L. McGinnis, M. Elimelech, A novel ammonia-carbon dioxide forward (direct) osmosis desalination process, Desalination, 174 (2005) 1-11.

[4] J.R. McCutcheon, R. Wang, Osmotic processes for a sustainable 21st century, Desalination, $312(2013) 1-1$.

[5] S. Phuntsho, S. Hong, M. Elimelech, H.K. Shon, Forward osmosis desalination of brackish groundwater: Meeting water quality requirements for fertigation by integrating nanofiltration, $\mathrm{J}$ Membrane Sci, 436 (2013) 1-15.

[6] S. Phuntsho, H.K. Shon, S. Hong, S. Lee, S. Vigneswaran, A novel low energy fertilizer driven forward osmosis desalination for direct fertigation: Evaluating the performance of fertilizer draw solutions, J Membrane Sci, 375 (2011) 172-181.

[7] A.D. Wilson, Design of the next-Generation FO Draw Solution, in: Rational Design of Nextgeneration Nanomaterials and Nanodevices for Water Applications, International Water Association (IWA), 2016, pp. 103-130.

[8] J.E. Miller, L.R. Evans, Forward Osmosis: A New Approach to Water Purification and Desalination, in, Sandia National Laboratory, Albuquerque, New Mexico, 2006.

[9] R.L. McGinnis, N.T. Hancock, M.S. Nowosielski-Slepowron, G.D. McGurgan, Pilot demonstration of the $\mathrm{NH} 3 / \mathrm{CO} 2$ forward osmosis desalination process on high salinity brines, Desalination, 312 (2013) 67-74.

[10] R.L. McGinnis, M. Elimelech, Energy requirements of ammonia-carbon dioxide forward osmosis desalination, Desalination, 207 (2007) 370-382. 
[11] N.T. Hancock, P. Xu, D.M. Heil, C. Bellona, T.Y. Cath, Comprehensive Bench- and PilotScale Investigation of Trace Organic Compounds Rejection by Forward Osmosis, Environ Sci Technol, 45 (2011) 8483-8490.

[12] C.J. Orme, A.D. Wilson, 1-Cyclohexylpiperidine as a thermolytic draw solute for osmotically driven membrane processes, Desalination, 371 (2015) 126-133.

[13] A.D. Wilson, C.J. Orme, Concentration dependent speciation and mass transport properties of switchable polarity solvents, Rsc Adv, 5 (2015) 7740-7751.

[14] D.S. Wendt, C.J. Orme, G.L. Mines, A.D. Wilson, Energy requirements of the switchable polarity solvent forward osmosis (SPS-FO) water purification process, Desalination, 374 (2015) 81-91.

[15] A.D. Wilson, F.F. Stewart, Deriving osmotic pressures of draw solutes used in osmotically driven membrane processes, J Membrane Sci, 431 (2013) 205-211.

[16] A.D. Wilson, F.F. Stewart, Structure-function study of tertiary amines as switchable polarity solvents, Rsc Adv, 4 (2014) 11039-11049.

[17] J.S. McNally, B. Noll, C.J. Orme, A.D. Wilson, Density Functional Theory Analysis of the Impact of Steric Interaction on the Function of Switchable Polarity Solvents, J Phys Chem B, 119 (2015) 6766-6775.

[18] T. Kamada, T. Ohara, T. Shintani, T. Tsuru, Controlled surface morphology of polyamide membranes via the addition of co-solvent for improved permeate flux, J Membrane Sci, 467 (2014) 303-312.

[19] K.J. Martin, D. Bolster, N. Derlon, E. Morgenroth, R. Nerenberg, Effect of fouling layer spatial distribution on permeate flux: A theoretical and experimental study, J Membrane Sci, 471 (2014) 130-137.

[20] A. Shrestha, J. Pellegrino, S.M. Husson, S.R. Wickramasinghe, A modified porometry approach towards characterization of MF membranes, J Membrane Sci, 421 (2012) 145-153. [21] W.A. Phillip, J.S. Yong, M. Elimelech, Reverse Draw Solute Permeation in Forward Osmosis: Modeling and Experiments, Environ Sci Technol, 44 (2010) 5170-5176.

[22] X.X. Song, Z.Y. Liu, D.R.D.L. Sun, Nano Gives the Answer: Breaking the Bottleneck of Internal Concentration Polarization with a Nanofiber Composite Forward Osmosis Membrane for a High Water Production Rate, Adv Mater, 23 (2011) 3256-+.

[23] J.S. Yong, W.A. Phillip, M. Elimelech, Coupled reverse draw solute permeation and water flux in forward osmosis with neutral draw solutes, J Membrane Sci, 392 (2012) 9-17.

[24] K.K. Reimund, B.J. Coscia, J.T. Arena, A.D. Wilson, J.R. McCutcheon, Characterization and membrane stability study for the switchable polarity solvent N,N-dimethylcyclohexylamine as a draw solute in forward osmosis, J Membrane Sci, 501 (2016) 93-99.

[25] K. Guerra, J. Pellegrino, Development of a Techno-Economic Model to Compare Ceramic and Polymeric Membranes, Sep Sci Technol, 48 (2013) 51-65.

[26] M.F.J. Solomon, Y. Bhole, A.G. Livingston, High flux hydrophobic membranes for organic solvent nanofiltration (OSN)-Interfacial polymerization, surface modification and solvent activation, J Membrane Sci, 434 (2013) 193-203.

[27] H. Siddique, E. Rundquist, Y. Bhole, L.G. Peeva, A.G. Livingston, Mixed matrix membranes for organic solvent nanofiltration, J Membrane Sci, 452 (2014) 354-366. [28] J.D. Burgal, L.G. Peeva, S. Kumbharkar, A. Livingston, Organic solvent resistant poly(ether-ether-ketone) nanofiltration membranes, J Membrane Sci, 479 (2015) 105-116. 
[29] P. Marchetti, A.G. Livingston, Predictive membrane transport models for Organic Solvent Nanofiltration: How complex do we need to be?, J Membrane Sci, 476 (2015) 530-553.

[30] J. Campbell, J.D. Burgal, G. Szekely, R.P. Davies, D.C. Braddock, A. Livingston, Hybrid polymer/MOF membranes for Organic Solvent Nanofiltration (OSN): Chemical modification and the quest for perfection, J Membrane Sci, 503 (2016) 166-176.

[31] M. Schaepertoens, C. Didaskalou, J.F. Kim, A.G. Livingston, G. Szekely, Solvent recycle with imperfect membranes: A semi-continuous workaround for diafiltration, J Membrane Sci, 514 (2016) 646-658.

[32] M. Noronha, V. Mavrov, H. Chmiel, Simulation model for optimisation of two-stage membrane filtration plants - minimising the specific costs of power consumption, J Membrane Sci, 202 (2002) 217-232.

[33] N.V. Patil, T. Schotel, C.V.R. Gomez, V.A. Montesdeoca, J.J.W. Sewalt, A.E.M. Janssen, R.M. Boom, Continuous purification of galacto-oligosaccharide mixtures by using cascaded membrane filtration, J Chem Technol Biot, 91 (2016) 1478-1484. 


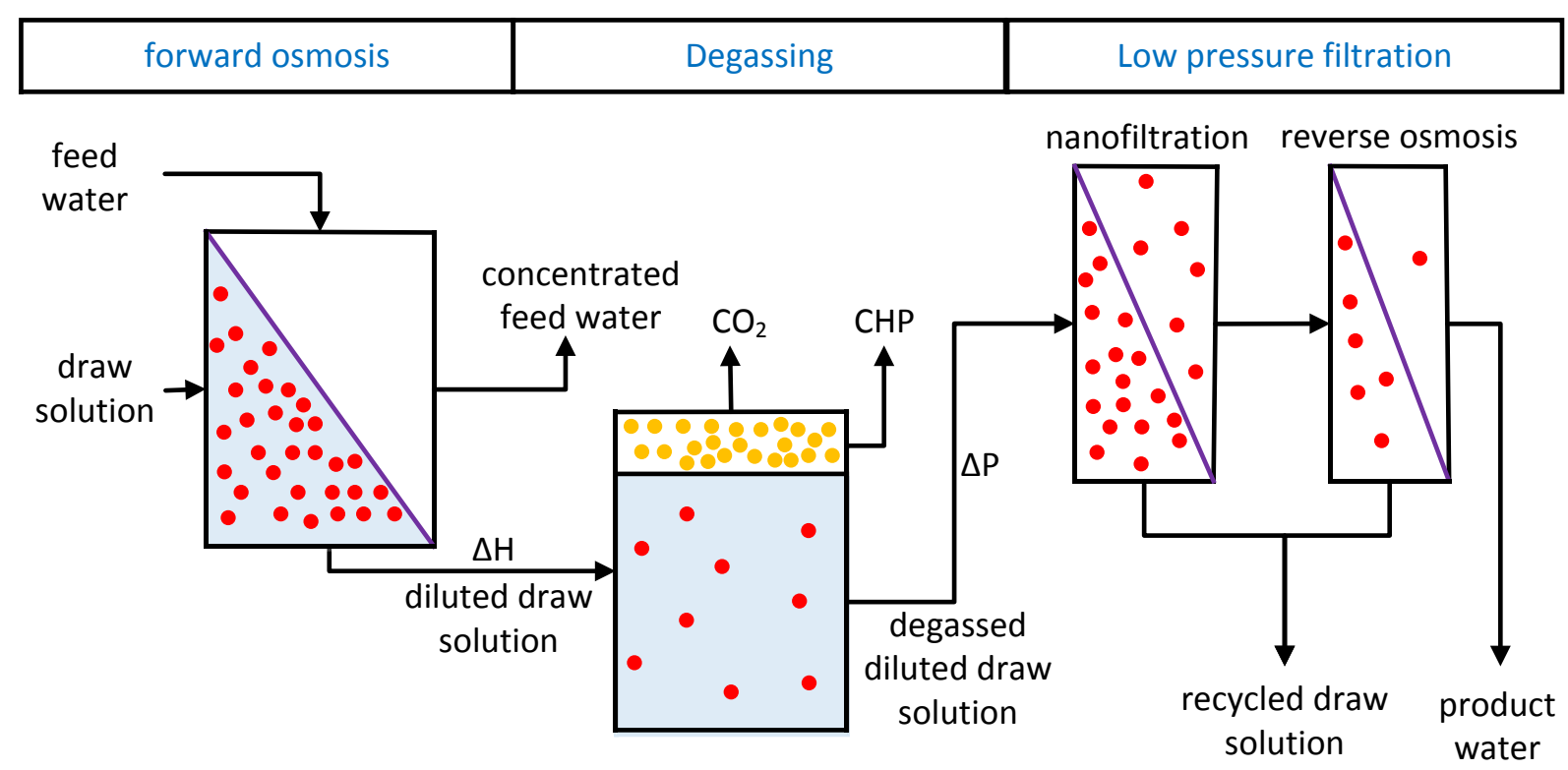

- $\mathrm{CHP} \quad \mathrm{CHP}_{-} \mathrm{H}_{2} \mathrm{CO}_{3}$ 